\title{
A study to assess knowledge about child development in caregivers attending the child psychiatry outpatient department
}

\author{
Shilpa Akkineni ${ }^{1}$, Phanikanth Kondaparthi ${ }^{2 *}$ \\ ${ }^{1}$ Postgraduate, ${ }^{2}$ Assistant Professor, Dept. of Psychiatry, Institute of Mental Health, Osmania Medical College, Hyderabad, Telangana, \\ India
}

*Corresponding Author: Phanikanth Kondaparthi

Email: aquarulzz@gmail.com

\begin{abstract}
Background: The initial years of child nurturing plays an important role in child development and lifelong learning. Parents' knowledge is considered to be the frame of reference for parents' interpretations of their child's behaviour and provides the basis for having the appropriate expectation of the child's developmental stage. When developmental delays are identified at the appropriate time, it increases the scope to initiate early intervention. Early intervention in children with developmental delay, can not only improve the overall disease outcome but also it provides support to family members.

Aim: To assess the caregivers' knowledge about child development and to study the association between caregivers' knowledge and sociodemographic parameters.

Materials and Methods: 110 Caregivers of children presenting to the child psychiatry OPD were screened for assessment criteria. A semistructured intake proforma was administered to collect the sociodemographic details. Caregiver knowledge of child developmental inventory was applied on caregivers to garner the responses.

Results: $84 \%$ of caregivers were mothers. On an average, caregivers were able to answer only $36 \%$ of the questions correctly. Maternal age $(\mathrm{p}=0.048)$ and maternal education $(\mathrm{p}=0.009)$ were identified to be significant predictors of higher CKCDI scores.

Conclusion: Caregiver's knowledge regarding the child development is low. Younger mothers and higher maternal education are associated with higher knowledge about the development of their children.
\end{abstract}

Keywords: Child development, Caregiver's knowledge.

\section{Introduction}

Developmental milestones are a specific set of skills that are achieved by the child as a result of interaction with the environment. Usually, one is able to determine the age of achievement of each developmental milestone. Classification of developmental milestones is as follows: gross motor, fine motor, socio-emotional, language and cognitive. ${ }^{1}$

Gross motor skills are those skills which involve large muscle groups of the body to perform daily activities like walking, running, standing, sitting, throwing and catching. Fine motor skills refer to those skills which require the use of small muscles that control the movement of hands and fingers. This enables the child to eat, write and to do other fine activities such as buttoning, zippering etc. Language development is the process by which children can understand and communicate effectively with others. Cognitive development is the construction of thought processes, which includes memory, judgement, problem solving and decision-making. Social-emotional development includes the child's experience, expression, and management of emotions and the ability to establish positive and rewarding relationships with others. ${ }^{1}$

Nervous system apparently needs a certain amount of stimulation to function properly. A significant lag in reaching the typical childhood developmental milestones in the areas of motor, language, cognition, social and emotional functioning is referred to as developmental delay. $^{2}$

As per the report given by WHO, around 5\% of children under the age of 14 years suffer from developmental delay and approximately $2 \%$ of children under 2 years of age suffer from developmental delay. ${ }^{3} \mathrm{~A}$ study conducted by Kaur P et al in 2006 studied the clinical profile of children attending an early intervention program. Their study revealed that majority of the children suffered from mental retardation, others had a diagnosis of cerebral palsy and epilepsy. Learning disorders, ADHD and autism were also seen in few children. ${ }^{4}$

In India, mean age of referral to early intervention programs was found to be 3-4 years. This is in contrast with a study done in USA where the mean age of referral was 1.2 years. This difference could be accounted due to the stigma associated with seeking help from special institutes in developing countries. ${ }^{5}$

When a child with developmental delay receives timely and appropriate services such as therapies in the form of occupational therapy, physical therapy or speech therapy, it has shown to result in positive outcomes. Increased intellectual competence, less disruptive and aggressive behaviour, more parental involvement in schooling, better academic performance and improved work skills are some of the noted benefits of early intervention. ${ }^{6}$

A RCT conducted to examine the effectiveness of a 6month early intervention program versus traditional home visiting in children with developmental delay, found that the group that received early intervention showed faster progress rate in self-care functions $(\mathrm{p}=0.006$, cohen's $\mathrm{d}=0.87$ ) and independence in social functions $(\mathrm{p}=0.027$, cohen's $\mathrm{d}=0.83) .^{7}$ 
The term "knowledge" refers to facts, information, and skills gained through experience or education and understanding of an issue or phenomenon.

Caregiver is defined as a non-professional person in the community who is mostly involved in everyday care of the child and one who attends to the needs of the child. ${ }^{8}$ Caregiver's knowledge is defined as understanding of developmental milestones, processes of child development and adapting caregiving skills by caregivers. The effective parent-child interaction and promoting development of children is dependent on the knowledge and awareness of parents to understand the processes of normal child development, caregiving skills as well as familiarity with child-care skills. ${ }^{9}$

Parental expectations and interactions with their child are influenced by their existing knowledge of child development. High parenting efficacy and competence was seen in those parents who had a sound knowledge about child development. ${ }^{10}$

Parental awareness about parenting and child development plays an important role in cognitive motivation which in turn promote cognitive, emotional and social competency of the child. Therefore, parental knowledge is one of the important aspects of child nurturing, more knowledgeable parents are more effective for their children. ${ }^{9}$

Research from developing countries have focused primarily on weight and nutritional status of the child and limited literature is available with regards to parental perceptions of child development. ${ }^{11}$ Hence, there is a need to assess the level of knowledge about child development among caregivers as it plays a vital role in accessing health care facilities.

\section{Aim}

1. To assess the caregiver's knowledge about child development.

2. To study the association between the caregiver's level of knowledge and sociodemographic parameters.

\section{Materials and Methods \\ Study design}

A cross sectional, outpatient-based study was conducted in the department of child psychiatry, Niloufer hospital, Hyderabad, India.

\section{Study subjects}

A convenient sample of 110 caregivers accompanying the child were recruited for the study.

\section{Inclusion criteria}

1. Male and Female

2. Caregivers of children below 12years presenting to child psychiatry OPD.

\section{Exclusion criteria}

1. Not willing to give consent.
2. Caregivers who had previously provided care to a child with delayed milestones.

\section{Instruments used}

1. All sociodemographic and clinical details were captured using a semi structured proforma: Caregiver's relation, parent's age, parent's education, parent's occupation, socioeconomic status, family type, religion, domicile, parity, whether provided care for another child with delayed milestones, assistance for childcare, age of child, diagnosis, duration of illness, mode of referral, time spent with health care worker.

2. Caregiver knowledge of child development inventory [12] : this questionnaire consists of a total of 20 questions. It is further divided into 3 components (i) component 1 - cognitive and social-emotional development of young infants (ii) component 2 cognitive and social-emotional development of toddlers (iii) component 3 - gross and fine motor development. Each question has a maximum score of 2 and a minimum score of 0 . Higher scores indicate higher level of knowledge. Answers that fall within the correct range were given 2 points. Answers that fall 1 month below or above the correct ranges were given 1 and all other answers considered incorrect were given 0 points. Internal consistency was evaluated by Cronbach alpha and was found to be 0.61 for the total scale. The construct validity was determined by factory analysis and all questions except question 20 had a loading of 0.30 .

\section{Methodology}

Caregivers' of patients attending the child psychiatry OPD were screened for assessment criteria. A key caregiver was identified. Out of the total caregivers attending the child psychiatry outpatient department during the period of the study, 110 caregivers fulfilled the recruitment criteria and were willing to give consent for participation in the study. Caregivers who had previously provided care to a child with delayed milestones will be equipped with prior knowledge because of the interaction with healthcare professionals earlier. Hence, those caregivers were excluded as there is a possibility of information bias amongst them. Study details were explained and a written informed consent was undertaken. A semi structured proforma was administered to collect the sociodemographic details. Caregiver knowledge of child developmental inventory was administered. Completed forms were scored and data entry was done.

\section{Statistical analysis}

Statistical analysis was performed using SPSS version 20 software. For analysing the level of knowledge among caregivers, descriptive statistics of each item was determined. The effect of independent sociodemographic and clinical variables on CKCDI scores were assessed using linear regression model. 


\section{Ethical aspects}

Ethics clearance was given by the Institute Ethics Committee (Reg. No. ECR/300/Inst/AP/2013/RR-19). Informed consent was taken from the participants of the study. Individuals had the right to withdraw their consent from participation any time after inclusion into the study. Individual's non participation did not have any bearing on their treatment. The identity of the individual was kept confidential. The scale included in the study is freely available in the public domain for research and academic purposes.

\section{Results}

\section{Sociodemographic characteristics}

A total of 110 caregivers were interviewed. Majority of the caregivers were identified to be mothers (84.6\%). On an average, mothers were found to be of $29.6(\mathrm{SD}=6.8)$ years and mean age of fathers was $35.7(\mathrm{SD}=7.4)$ years. Majority of mothers $(46.2 \%)$ and fathers $(52.3 \%)$ received education up to secondary level. Most of the mothers were unemployed $(76.9 \%)$ and most of the fathers were semiskilled workers $(50.9 \%)$. Most of the children were brought up in nuclear families $(58.5 \%)$ and were from urban background $(70.8 \%)$. Almost one fourth of the children were single children. A majority of the mothers did not receive assistance for child care $(60 \%)$. Most children were diagnosed to be suffering from mental retardation and their mean age was 5.25 years. $75 \%$ of the children presented to the child psychiatrist through a medical channel. Average duration of illness was found to be 3.3 years. Most caregivers reported that they had spent an average of 4.1 hours with health care worker. (Table 1).

\section{Knowledge of developmental milestones}

The results revealed that the mean score on CKCDI questionnaire scale was $14.45( \pm 5.8)$. The mean score in component 1 was $3.29( \pm 2.9)$, component 2 was $5.6( \pm 3.0)$ and component 3 was 3.57 ( \pm 2.0$)$. Most caregivers were able to answer correctly to questions such as, when to notice social smile in their children $(54 \%)$, at what age do children begin imaginary play $(66 \%)$ and when should children be taught to count numbers $(66 \%)$. A major portion of the caregivers were unaware of the correct age of development of the brain $(80 \%)$, the age at which children begin to give verbal responses to someone talking to them $(73.8 \%)$, the age at which children start to follow moving objects with their eyes $(77.4 \%)$, the appropriate age at which mothers should begin to talk to their child $(87.7 \%)$ and the age at which mothers should encourage reading books with their children (97\%). (Table 2)

Using linear regression model, correlation between the sociodemographic parameters and the scores obtained was performed. This analysis revealed that there was no significant correlation between the scores obtained and relation of the caregiver, family type, domicile, parity, occupation of the parents, socioeconomic status, religion, paternal age and education. However maternal age $(\mathrm{p}=0.048)$ and education $(\mathrm{p}=0.009)$ were found to be independent predictors of higher scores. (Table 3 )

Table 1: Sociodemographic characteristics

\begin{tabular}{|l|c|c|c|}
\hline Parameter & $(\%)$ & Mean & SD \\
\hline Relation with child & & & \\
\hline Mother & 84.6 & & \\
\hline Father & 15.4 & & \\
\hline Maternal age (years) & & 29.6 & 6.8 \\
\hline Paternal age (years) & & 35.7 & 7.4 \\
\hline Maternal education & & & \\
\hline Illiterate & 20 & & \\
\hline Primary & 13.8 & & \\
\hline Secondary & 46.2 & & \\
\hline Undergraduate & 20 & & \\
\hline Postgraduate & 0 & & \\
\hline Paternal education & & & \\
\hline Illiterate & 20 & & \\
\hline Primary & 6.2 & & \\
\hline Secondary & 52.3 & & \\
\hline Undergraduate & 21.5 & & \\
\hline Postgraduate & 0 & & \\
\hline Maternal occupation & & & \\
\hline Unemployed & 76.9 & & \\
\hline Unskilled & 15.4 & & \\
\hline Semiskilled & 4.6 & & \\
\hline Skilled & 3.1 & & \\
\hline Paternal occupation & & & \\
\hline Unemployed & 1.5 & & \\
\hline
\end{tabular}




\begin{tabular}{|c|c|c|c|}
\hline Unskilled & 21.5 & & \\
\hline Semiskilled & 50.9 & & \\
\hline Skilled & 20 & & \\
\hline \multicolumn{4}{|l|}{ Socioeconomic status } \\
\hline Below poverty line & 6.4 & & \\
\hline Lower & 11.7 & & \\
\hline Lower middle & 21.2 & & \\
\hline Higher middle & 33.8 & & \\
\hline Higher & 26.9 & & \\
\hline \multicolumn{4}{|l|}{ Family type } \\
\hline Nuclear & 58.5 & & \\
\hline Joint & 41.5 & & \\
\hline \multicolumn{4}{|l|}{ Domicile } \\
\hline Urban & 70.8 & & \\
\hline Rural & 29.2 & & \\
\hline \multicolumn{4}{|l|}{ Religion } \\
\hline Hindu & 42.7 & & \\
\hline Christian & 31.2 & & \\
\hline Muslim & 26.1 & & \\
\hline \multicolumn{4}{|l|}{ Parity } \\
\hline Single & 24.6 & & \\
\hline Multiple & 75.4 & & \\
\hline \multicolumn{4}{|l|}{ Assistance for childcare } \\
\hline Yes & 40 & & \\
\hline No & 60 & & \\
\hline \multicolumn{4}{|l|}{ Diagnosis } \\
\hline Mental retardation & 57.6 & & \\
\hline Disorders of psychological development & 23.9 & & \\
\hline Behavioural and emotional disorders with onset in childhood and adolescence & 18.5 & & \\
\hline Age of Child (years) & & 5.25 & 3.1 \\
\hline \multicolumn{4}{|l|}{ Mode of referral } \\
\hline Medical & 75.4 & & \\
\hline Non medical & 24.6 & & \\
\hline Duration of Illness(years) & & 3.3 & 1.7 \\
\hline Time spent with health care worker (hours) & & 4.1 & 2.6 \\
\hline
\end{tabular}

Table 2: Caregiver Knowledge of Child Development Inventory

\begin{tabular}{|l|c|c|c|}
\hline Questions & $\begin{array}{c}\text { \% incorrect } \\
\text { answers }\end{array}$ & $\begin{array}{c}\text { Mean answer } \\
\text { (months) }\end{array}$ & $\begin{array}{c}\text { SD } \\
\text { (months) }\end{array}$ \\
\hline When does a child's brain begin to develop and learn? & 80.4 & 64 & 6.8 \\
\hline When do children begin to see ? & 50.8 & 2.5 & 3.3 \\
\hline $\begin{array}{l}\text { When do children begin to follow a moving person or toy, with their } \\
\text { eyes? }\end{array}$ & 77.4 & 8.95 & 4.45 \\
\hline $\begin{array}{l}\text { When do children begin to vocalize in response to someone talking to } \\
\text { them? }\end{array}$ & 73.8 & 7.96 & 5.5 \\
\hline $\begin{array}{l}\text { When do children begin to smile socially, that is smile into the face of } \\
\text { another person? }\end{array}$ & 46.2 & 5.2 & 5.3 \\
\hline When do children begin to say single meaningful words? & 35.4 & 11.9 & 5.6 \\
\hline $\begin{array}{l}\text { When do children begin to play imaginary play like feeding a doll or } \\
\text { driving a toy car? }\end{array}$ & 34.0 & 12.3 & 7.0 \\
\hline When do children begin to reach for a toy in front of them? & 80 & 8.8 & 4.0 \\
\hline $\begin{array}{l}\text { When do children begin to grasp tiny things like raisins, with their } \\
\text { fingertips? }\end{array}$ & 53.8 & 9.8 & 4.7 \\
\hline $\begin{array}{l}\text { When do children begin to walk alone with good co- } \\
\text { ordination? }\end{array}$ & 30.8 & 11.6 & 4.4 \\
\hline
\end{tabular}




\begin{tabular}{|l|c|c|c|}
\hline When should mothers begin to talk to children? & 87.7 & 9.1 & 6.8 \\
\hline $\begin{array}{l}\text { When should mothers begin to show colorful objects to children to help } \\
\text { them practice reaching? }\end{array}$ & 83.1 & 8.8 & 6.2 \\
\hline When should mothers begin to teach children to count? & 33.8 & 15.1 & 9.6 \\
\hline When should mothers begin to teach children colors? & 40 & 14.3 & 10.1 \\
\hline $\begin{array}{l}\text { When should mothers start to give children a spoon or a fork to let them } \\
\text { eat by themselves? }\end{array}$ & 60 & 18.0 & 12.5 \\
\hline $\begin{array}{l}\text { When should mothers begin to let children sit with } \\
\text { support? }\end{array}$ & 65.2 & 9.7 & 4.1 \\
\hline $\begin{array}{l}\text { When should mothers begin to give children clean and safe objects or } \\
\text { toys which they can mouth? }\end{array}$ & 43.1 & 9.3 & 7.9 \\
\hline $\begin{array}{l}\text { When should mothers begin to look at children's books with their } \\
\text { children? }\end{array}$ & 96.9 & 14.11 & 12.3 \\
\hline $\begin{array}{l}\text { When should mothers begin to give children clean and safe household } \\
\text { items to play with? }\end{array}$ & 44.6 & 9.8 & 7.8 \\
\hline
\end{tabular}

Component 1: cognitive and social-emotional development of young infants; component 2: cognitive and social emotional development of toddlers; component 3: gross and fine motor development.

Table 3: CKCDI mean total scores and sociodemographic correlates

\begin{tabular}{|l|c|c|}
\hline Parameter & 'p' value & Test statistic \\
\hline Maternal Age & $0.048^{*}$ & $\mathrm{t}=3.721$ \\
\hline Paternal Age & 0.091 & \\
\hline Maternal Education & $0.009^{*}$ & $\mathrm{x}^{2}=4.06$ \\
\hline Paternal Education & 0.072 & \\
\hline Maternal Occupation & 0.161 & \\
\hline Paternal Occupation & 0.301 & \\
\hline Family type & 0.078 & \\
\hline Parity & 0.088 & \\
\hline Domicile & 0.731 & \\
\hline Socioeconomic status & 0.095 & \\
\hline Religion & 0.513 & \\
$* \mathrm{p}<0.05$ & & \\
\hline
\end{tabular}

\section{Discussion}

The current study aimed at exploring the knowledge possessed by caregivers regarding child development. There is quite a large research base dwelling into parenting practices and child outcome, however limited research is available with respect to caregiver's knowledge about child development. Since caregiver's knowledge lays the foundation to influence their behaviour and care giving practices, it eventually contributes in impacting the overall wellbeing of the child.

Our study revealed that the overall knowledge concerning child development is low with a mean score obtained on CKCDI to be $36 \%$ of the total. Similar score has been reported in a study conducted by Shrestha et al. (2017) where the mean score obtained was $40 \%$ of the total. ${ }^{13}$ Another study by Arulmurugun et al. (2020) stated that only $50 \%$ of the mothers could accurately estimate child developmental milestones, and $27 \%$ of them had underestimated whereas $18 \%$ overestimated child developmental milestones. ${ }^{14}$ This may be a reflection of the fact that in developing countries the major source of knowledge is based on informal sources like discussing with relatives and comparing with siblings. In India, there are both, familial and cultural sources of information from which caregivers derive their beliefs about child development. ${ }^{15}$

Estimating the appropriate timing of developmental milestones has dire consequences. Firstly, underestimating the age of achievement can lead to caregivers being anxious and intolerant of their child's behaviour. This may also pose a risk for child abuse. Whereas, overestimating the age of achievement can lead to under stimulation of the child to help them develop necessary skills and more importantly they can miss the opportunity to detect developmental delay.

In our study population majority of the participants (80\%) were unaware of the timing of brain development. This is comparable to the study conducted by Zellman et al where it was found that less than $15 \%$ believed that brain development occurs in the perinatal period. ${ }^{16}$ It is important for caregivers especially mothers to understand this, as perinatal maternal malnutrition, exposure to toxic substances, maternal infections and certain medications can interfere with healthy brain development of the fetus and being aware of this would encourage mothers to take 
necessary precautions to reduce the risk of abnormalities in brain development.

Strikingly $74 \%$ of caregivers were unable to tell the age at which children start to give verbal responses to someone talking to them. According to a study conducted by Ertem et al (2007) $79 \%$ of mothers did not know that vocalisation occurs in the early months of life. ${ }^{12}$ There is considerable evidence that when children are encouraged to initiate and sustain a conversation by simply talking to them more frequently, it can result in better vocabulary development. Apart from talking to children more often, the quality of language used by caregivers affects the vocabulary of their child. ${ }^{17}$

This study found that $66 \%$ of the caregivers did know when to initiate imaginary play among children. Imaginary play provides opportunity to think and express emotions. It can also enhance the ability of the child to have an alternative understanding of a particular situation, it teaches them new ways to react to situations and also to realise the cause-and-effect nature of relationships. ${ }^{18}$

It was observed that most caregivers $(66 \%)$ took the initiative to teach their children to count numbers. It is demonstrated that in families where children are involved in number talk during daily routine, have a higher chance of success in later math achievement. ${ }^{19}$

The larger number of mothers $(97 \%)$ were unable to determine when to start reading books with their children. This is congruent with Ertem et al (2017) where 95.2\% of them answered incorrectly. It was also found that this activity was least known among the mothers. However shared book reading by parents carries multi-fold significance. It helps children understand that spoken language can be represented visually, improves their phonological awareness, children begin to understand language and syntax better as well as learn new concepts and story structure. Book reading on a daily basis inculcates the habit of establishing routines and contributes in shaping sleep wake patterns. ${ }^{20}$

Maternal education played a significant role in determining the total score obtained and more specifically to the cognitive and social emotional development of toddlers. $(\mathrm{p}=0.009)$. This finding is congruent to the results published in a study by Borstein et al. where mothers who were more educated had higher CKCDI scores $(\mathrm{p}<0.001)$. Mothers who are well educated believed that they have the ability to change and improve the environment. ${ }^{21}$ They were also more vigilant about their children's behaviour and any deviation from the normal was easily noticed by them. Parents who are more aware of child development tend to interact more positively with their children as compared to those who have lesser knowledge. Such parents also have realistic expectations for their child which improves the quality of parent child interaction. ${ }^{22}$

Our study found that younger mothers significantly scored more on CKCDI $(\mathrm{p}=0.048)$. However, this finding is in contrast to the study conducted by Safadi et al (2016) where no correlation was found between the level of knowledge and maternal age. ${ }^{23}$ This difference might be attributable to the fact that in our study sample younger mothers were more highly educated.

\section{Limitations}

One of the limitations is that, this study did not explore into the cultural practices and beliefs about child rearing. Second, the level of knowledge was assessed only in one key caregiver. A more elaborative analysis in other family members may reflect the overall level of knowledge about child development, which can influence the help seeking behaviour of the caregiver. Further due to small sample size and as convenient sampling was used, the findings of the study cannot be projected to general population.

\section{Conclusion}

Caregiver's knowledge regarding child development appears to be low. Caregiver's sociodemographic parameters had little influence on the overall level of knowledge. Future studies can further assess how cultural practices and child rearing beliefs influence child development. The results of this study suggest that increasing the awareness about child development among caregivers especially mothers can be beneficial.

\section{Future Direction}

Beliefs and attitudes related to child development and factors that are associated with maternal knowledge need to be further investigated. This helps us to plan for culture specific, focused and effective interventions.

The CKCDI may be employed as an instrument to determine caregiver knowledge of child development, so that caregivers who are in greater need for information can be addressed.

\section{Source of Funding}

Nil.

\section{Conflicts of Interest}

There are no conflicts of interest.

\section{References}

1. Dosman CF, Andrews D, Goulden KJ. Evidence-based milestone ages as a framework for developmental surveillance. Paediatr Child Health. 2012;17(10):561-8.

2. Pietrangelo A. Developmental delay: Symptoms, causes, treatment \& more. Healthline.com. 2020

3. Developmental Delay/Delayed Milestones. Institute of Child Development. Government of India. Available from: http://www.icddelhi.org/developmental_delayed_milesto ne.html

4. Kaur P, Chavan BS, Lata S, Kaur A, Tinku S, Arora Y, et al. Early intervention in developmental delay. Indian J Pediatr. 2006;73(5):405-8.

5. Juneja M, Mukherjee SB, Sharma S. A descriptive hospital based study of children with autism. Indian Pediatr. 2005;42(5):453-8.

6. Scharf RJ, Scharf GJ, Stroustrup A. Developmental milestones. Pediatr Rev. 2016;37(1):25-37.

7. Hwang AW, Chao MY, Liu SW. A randomized controlled trial of routines-based early intervention for children with or at risk 
for developmental delay. Res Dev Disabil. 2013;34(10):311223.

8. Falloon RH, Graham Hole V, Woodroffe R. Stress and health of informal carers of people with chronic mental disorders. $J$ Ment Health. 1993;2:165-73

9. Habibi E, Sajedi F, Malek Afzali H, Hatamizadeh N, Shashahanipour S, Glascoe FP. Early childhood development and Iranian parents' Knowledge: A qualitative study. Int J Prev Med. 2017;8:84.

10. Reich S. What do mothers know? Maternal knowledge of child development. Infant Ment Health J. 2005;26(2):143-56.

11. Hochdorn A, Baldi I, Paramesh EC, Kumar M, Gulati A, Gregori D. Is my kid out of size? Indian mothers' desirability Bias in evaluation of their Children's weight. Indian J Pediatr. 2014;81(1):39-46.

12. Ertem IO, Atay G, Dogan DG, Bayhan A, Bingoler BE, Gok $\mathrm{CG}$, et al. Mothers' knowledge of young child development in a developing country. Child Care Health Dev. 2007;33(6):72837.

13. Merina Shrestha, Manjeswori Ulak, Tor A. Strand, Ingrid Kvestad \& Mari Hysing. How much do Nepalese mothers know about child development. Early Child Dev Care. 2019;189(1):135-42.

14. Karuppannan A, Ramamoorthy T, Rammamoorthi A et.al. Mother's knowledge on child's developmental milestones and parenting skills in Kanchipuram district, Tamilnadu - a descriptive cross sectional study. Int J Health Sci Res. 2020;10(2):242-7.

15. Tuli M, Chaudhary N. Elective interdependence: understanding individual agency and interpersonal relationships in Indian families. Cult Psychol. 2020;16:477-96.

16. Zellman GL, Karam R, Perlman M. Predicting child development knowledge and engagement of Moroccan parents. Near Middle East J Res Educ. 2014;2014(1):5.
17. National Academies of Sciences, Engineering, and Medicine, Division of Behavioral and Social Sciences and Education, Board on Children, Youth, and Families, Committee on Supporting the Parents of Young Children, Breiner H, Ford M, et al. Parenting knowledge, attitudes, and practices. Washington, D.C., DC: National Academies Press; 2016.

18. Scott HK, Cogburn M. Peer Play. In: StatPearls. Treasure Island (FL): StatPearls Publishing; 2020.

19. El Nokali NE, Bachman HJ, Votruba-Drzal E. Parent involvement and children's academic and social development in elementary school: Parent involvement, achievement, and social development. Child Dev. 2010;81(3):988-1005.

20. Duursma E, Augustyn M, Zuckerman B. Reading aloud to children: The evidence. Arch Dis Child. 2008;93(7):554-7.

21. Bornstein MH, Cote LR, Haynes OM, Hahn C-S, Park Y. Parenting knowledge: Experiential and sociodemographic factors in European American mothers of young children. Dev Psychol. 2010;46(6):1677-93.

22. Okagaki L, Bingham GE. Parents' social cognitions and their parenting behaviors. In Parenting: An ecological perspective. 2005;2:3-33.

23. Safadi RR, Ahmad M, Nassar OS, Alashhab SA, Abdel KR, Amre HM. Jordanian mothers' knowledge of infants' childrearing and developmental milestones. Int Nurs Rev. 2015;63(1):50-9.

How to cite this article: Akkineni S, Kondaparthi P. A study to assess knowledge about child development in caregivers attending the child psychiatry outpatient department. Telangana J Psychiatry. 2020;6(2):153-159. 